\title{
Impact of Patient Reimbursement Timing and Patient Out-of-Pocket Expenses on Medication Adherence in Patients Covered by Private Drug Insurance Plans
}

\author{
François Després, BSc; Amélie Forget, MSc; Fatima-Zohra Kettani, MSc; and Lucie Blais, PhD
}

\begin{abstract}
BACKGROUND: Adherence to prescribed medications used in the treatment of chronic diseases is suboptimal, and drug insurance plans can have an impact on adherence. There is little evidence on the impact of patient reimbursement timing on medication adherence.
\end{abstract}

OBJECTIVE: To compare adherence to prescribed medications in privately insured patients from Quebec, Canada, with different patient reimbursement timing and levels of patient out-of-pocket expenses.

METHODS: A retrospective cohort was constructed by selecting privately insured patients aged 18-64 years from the reMed database (2008-2012) who filled at least 1 prescription for a medication belonging to 1 of the 10 most prescribed drug classes for chronic diseases. Patient reimbursement timing was classified as immediate (immediate patient reimbursement at the point of service of the portion of the medication cost covered by the insurer) or deferred (patient reimbursement at a later time). Patient outof-pocket expenses related to the medication under study at cohort entry (available only for the immediate patient reimbursement group), which included the deductible and the coinsurance, were categorized into 5 levels (null category and quartiles): $\$ 0, \$ 0.01-\$ 3.59, \$ 3.60-\$ 8.11, \$ 8.12-\$ 14.40$, and \$14.41-\$89.99. Adherence was measured with the proportion of days covered (PDC) over 1 year among new users of the medication under study. Linear regression models were used to estimate the adjusted mean difference of PDC between groups.

RESULTS: There was no difference in medication adherence between the immediate $(n=1,345)$ and deferred patient reimbursement $(n=437$; difference, $0.0 \% ; 95 \% \mathrm{Cl},-3.0$ to 3.0 ). Patients with the highest patient out-of-pocket expenses were less adherent than those with the lowest patient out-of-pocket expenses (difference, $-19.0 \%$; $95 \% \mathrm{Cl},-24.0$ to -13.0 ); however, patients with no patient out-of-pocket expenses were less adherent than those with low patient out-of-pocket expenses (difference, $-9.0 \%$; $95 \% \mathrm{Cl},-15.0$ to -2.0 ).

CONCLUSIONS: Medication adherence appeared to be unaffected by patient reimbursement timing but was affected by the level of patient out-of-pocket expenses. The absence of a correlation between medication adherence and timing of patient reimbursement might be explained by the relatively rapid reimbursement of expenses by insurance companies in Canada. Subjects with no patient out-of-pocket expenses at the point of service might be less adherent because they place less value on their medications than do patients who must pay even a small amount.

J Manag Care Spec Pharm. 2016;22(5):539-47

Copyright $\odot 2016$, Academy of Managed Care Pharmacy. All rights reserved.

\section{What is already known about this subject}

Adherence to prescribed medications used in the treatment of chronic diseases is suboptimal, and drug insurance plans can have an impact on adherence.

Higher patient out-of-pocket expenses reduce adherence to prescribed medications.

\section{What this study adds}

Deferred patient reimbursement (i.e., patient pays 100\% of the medication cost at the pharmacy and receives reimbursement by the insurer at a later time) had no impact on adherence to medications in patients covered by private drug insurance plans.

The level of patient out-of-pocket expenses affected medication adherence where higher patient out-of-pocket expenses reduced adherence to prescribed medications. However, patients with no out-of-pocket expenses were less adherent than patients with small out-of-pocket expenses.

工 ow adherence to prescribed medications used in the treatment of chronic diseases is a topic of concern. In 2003, the World Health Organization (WHO) reported an average nonadherence of $50 \%$ among patient with chronic diseases. ${ }^{1}$ According to the $\mathrm{WHO}$, adherence is a multidimensional phenomenon, influenced by an interplay of factors that can be grouped into 5 dimensions: (1) patient-related factors (demographic and psychosocial); (2) social and economic factors (health literacy, family income, and social support); (3) health care system factors (drug costs and copayment options); (4) condition- or disease-related factors (severity of symptoms); and (5) therapy-related factors (complexity of medication regimen and the presence of medication side effects). ${ }^{1-4}$ Private insurance companies in Canada often reimburse patients all, or a portion, of the medication cost. The patient reimbursement may be immediate (at the point of service) or deferred to a later time. Within the health care system factors, the type of drug insurance plan is likely to affect adherence to prescribed medications, since plans vary greatly in terms of drug coverage, patient reimbursement timing, and patient out-of-pocket expenses such as copayments (the fixed amount paid by the patient when a prescription is filled), coinsurance (the fixed 
percentage of the cost of the filled prescription), and deductibles (the amount spent by the patient before the drug insurance company begins to pay).

A literature review revealed that lack of drug insurance coverage and high patient out-of-pocket expenses can reduce adherence to prescribed medications. ${ }^{5}$ Indeed, several studies have shown that an increase in the copayment of $\$ 10$ was associated with a significant decrease in medication adherence, ranging from $2 \%$ to $6 \%{ }^{6-18}$ In addition, we found no studies that evaluated the impact of patient reimbursement timing, such as immediate (immediate patient reimbursement at the point of service of the portion of the medication cost covered by the insurance) or deferred (patient pays 100\% of the medication cost at the pharmacy and receives reimbursement by the insurance at a later time) on medication adherence. Based on the research on high patient out-of-pocket expenses and lower medication adherence, ${ }^{6-18}$ we hypothesized that subjects with deferred patient reimbursement would have lower adherence because they have to pay the entire cost of their medications at the point of service before they can be reimbursed by their insurance companies.

The purpose of this study was to compare adherence to prescribed medications in patients with deferred patient reimbursement with those with immediate patient reimbursement at the point of service. We also evaluated the impact of patient out-of-pocket expenses, such as coinsurance and deductibles, on medication adherence. This study was performed within a cohort of Canadians from the province of Québec covered by private drug insurance.

\section{Methods}

\section{Drug Plans in Québec}

In 1997, a universal drug insurance program was introduced by the government of Québec, Canada, requiring by law that every citizen of the province be covered either by private or public drug insurance. In 2012, 57\% of the Quebec population was covered by private drug insurance plans through their employers or their spouses' employers, while the remaining $43 \%$ were covered by the public drug insurance plan. ${ }^{19}$

Private plans selected by employers or unions vary in terms of premiums, deductibles, and coinsurance amounts, with the deductible generally ranging from $\$ 0$ to $\$ 100$ per year (all costs are expressed in Canadian dollars) and coinsurance ranging from $0 \%$ to $32 \%$. In 2012, the yearly maximum patient out-ofpocket expense for a patient on a private plan was $\$ 963$, and this ceiling was determined by the Régie de l'assurance maladie du Québec. In addition, according to the insurance plan, patients either pay the deductible and the coinsurance at the point of service (immediate patient reimbursement) or they pay the entire cost of the medication and are reimbursed at a later time (deferred patient reimbursement).

\section{Source of Data}

The reMed database was used for this study; this database stores routinely updated information related to prescribed medications filled at community pharmacies for a sample of residents of Quebec. The sample for this study consists of patients who were recruited in community pharmacies, medical clinics, and blood sampling centers in several areas in the province (Montreal area, Laval area, Montérégie, and the Eastern Townships), who are less than aged 65 years, who are covered by private drug insurance, and who have their medication claims electronically transferred by the pharmacist to the insurance company. Data related to prescribed medications are purchased from community pharmacies' computer services providers, who manage the data transmission required for patient and pharmacist reimbursement by private drug insurance companies. The reMed database has been previously used in similar drug utilization studies. ${ }^{20-22}$

For each patient enrolled in reMed, the database contains the patient's health care number (NAM), private insurance policy number (PIPN), date of birth, and sex, as well as data on the area of residence, weight, height, and smoking status at time of recruitment. The information in the database related to prescribed medications includes name, dose, formulation, and quantity of the prescribed medication; date the prescription was dispensed; an anonymized pharmacy and prescriber identifier; cost of the medication; and amount paid by insurance. As of December 31, 2012, a total of 18,841 privately insured patients were registered in reMed, with a signed consent form on record for all patients. This study was approved by the Scientific and Ethics Committee of the Hôpital du Sacré-Coeur de Montréal.

\section{Study Design}

A retrospective cohort of privately insured patients selected from reMed was used in this study. Privately insured patients were chosen because they represent 70\% of Quebecers aged 18-64 years, and use of this group allows the evaluation of the impact of patient reimbursement timing and patient outof-pocket expenses across multiple drug plans. The cohort included all patients registered in reMed aged 18-64 years who filled at least 1 prescription for a medication belonging to 1 of the 10 drug classes most prescribed for chronic diseases (antidepressants, antiepileptics, antihypertensives, antipsychotics, asthma and chronic obstructive pulmonary disease medications, antithrombotics, proton pump inhibitors, oral antidiabetics, statins, and thyroid hormones) between March 15, 2008, and December 31, 2012. For patients who filled medications from different drug classes, 1 medication was randomly selected. The cohort entry date was defined as the date of the first filled prescription of the selected medication recorded in reMed on or after March 15, 2008. We restricted our analysis to new users of a medication, defined as patients who did not 
fill a prescription for the medication under study during the year before cohort entry. Additionally, continued enrollment in the private drug insurance plan for at least 3 months after the date of cohort entry was required for inclusion. Patients were followed until the earliest of the following events: their 65th birthday, change from a private to a public drug insurance plan, change of private drug insurance plan, 1 year of followup, or December 31, 2013.

\section{Patient Reimbursement Timing and Patient Out-of-Pocket Expenses}

Patients were classified under immediate or deferred patient reimbursement. It is important to note that the reMed database only includes patients who have their medication claims electronically transferred by their pharmacists to their insurance companies. Therefore, patients who need to file insurance claims for medication reimbursement were not included in our study. For each prescription filled at the pharmacy, the pharmacist sends a claim to the patient's drug insurance company. For patients with immediate patient reimbursement, the pharmacist is reimbursed by the insurance company for the amount it covers, and the patient has only to pay the copayment and/or the deductible at the point of service. Because of this transaction between the pharmacy and the insurance company, the amount paid by the insurance company and the amount paid by the patient are recorded in the pharmacist's file and subsequently recorded in reMed. For a patient with deferred patient reimbursement, the pharmacist is not reimbursed by the insurance company, and the patient has to pay the entire cost of the medication at the point of service. The portion of the cost covered by the insurance company is then reimbursed to the patient at a later date. Because there are no transaction between the pharmacy and the insurance company, the amount paid by the insurance company and the patient are not recorded in the pharmacist's file and therefore not recorded in reMed.

Patient out-of-pocket expenses related to the medication under study at cohort entry, which included the deductible and the coinsurance, were categorized into 5 levels (null category and quartiles): $\$ 0, \$ 0.01-\$ 3.59, \$ 3.60-\$ 8.11, \$ 8.12-\$ 14.40$, and \$14.41-\$89.99. We also considered patient out-of-pocket expenses related to all medications dispensed on the same day as the medication under study (i.e., at cohort entry), which were categorized (null category and quartiles) as $\$ 0, \$ 0.01-\$ 5.60$, \$5.61-\$11.78, \$11.79-\$21.02, and \$21.03-\$287.60. Because of the wide range of the highest quartile of patient out-of-pocket expenses and the concern of variable adherence level within this quartile, we examined the range of medication adherence within this highest quartile as a post hoc analysis. To do so, we subdivided the highest quartile into 4 subgroups (quartiles) of equal size; we estimated the level of adherence within each of these subgroups, and we did a l-way analysis of variance (ANOVA) to test for difference in the level of adherence among the 4 subgroups. This analysis was done for the medica- tion under study and for all medications dispensed at cohort entry. Patient out-of-pocket expenses were calculated only for patients with immediate patient reimbursement because the amount paid by the insurance company for deferred patient reimbursement is not recorded in the pharmacist's file and therefore not recorded in reMed.

\section{Outcome Variable}

Patient adherence, defined as the extent to which patients take medications as prescribed by their physicians, was measured for the medication under study for up to 1 year following cohort entry using proportion of days covered (PDC). ${ }^{4}$ It is worth noting that we measured adherence to the class of medication under study, and switches between medications of the same class were not considered as treatment discontinuation. PDC, which is defined as the number of days supply of the medication during the follow-up period divided by the number of days of follow-up, is the measure of adherence recommended by the National Quality Forum and Pharmacy Quality Alliance. ${ }^{23,24}$

\section{Potential Confounders}

The variables measured at cohort entry were age (18-34, 35-49, and 50-64 years); sex; calendar year (2008-2012); and class of the medication under study. We also recorded the patient's body mass index (BMI) using the WHO classification system (underweight, BMI $<18.5 \mathrm{~kg} / \mathrm{m}^{2}$; normal, $18.5 \mathrm{~kg} / \mathrm{m}^{2} \leq \mathrm{BMI}<25.0 \mathrm{~kg} / \mathrm{m}^{2}$; overweight, $25.0 \mathrm{~kg} / \mathrm{m}^{2} \leq \mathrm{BMI}<30.0 \mathrm{~kg} / \mathrm{m}^{2}$; and obese, $\mathrm{BMI} \geq 30.0 \mathrm{~kg} / \mathrm{m}^{2}$ ) and smoking status (nonsmoker, ex-smoker, or smoker), as recorded at registration in reMed. Finally, we used filled prescriptions recorded in reMed in the year before cohort entry to determine the number of different medications used per patient $(0-2,3-4,5-6$, and $7+)$, using the Anatomic Therapeutics Chemical Classification System codes.

\section{Statistical Analyses}

Patient characteristics were summarized using means and standard deviations (SDs) for continuous variables and proportions for categorical variables. The mean PDC and SD were estimated separately for patients with deferred and immediate patient reimbursement. In addition, linear regression models were used to compare the levels of adherence between patients with deferred and immediate patient reimbursement while adjusting for age, sex, BMI, smoking status, and the number of different medications filled in the year before cohort entry. The final model was obtained using a backward selection procedure, starting with a model that included all the potential confounders listed above. We removed every covariate that did not act as a confounder, as well as those that were not significantly associated with the outcome $(P>0.05) .{ }^{25}$ A covariate was considered as a confounder if its removal from the model modified the $\beta$ value associated with the patient reimbursement timing by $>10 \%$. 


\section{FIGURE 1 Study Cohort Flowchart}

Patients registered in the reMed database as of December 31, 2012 $n=18,841$

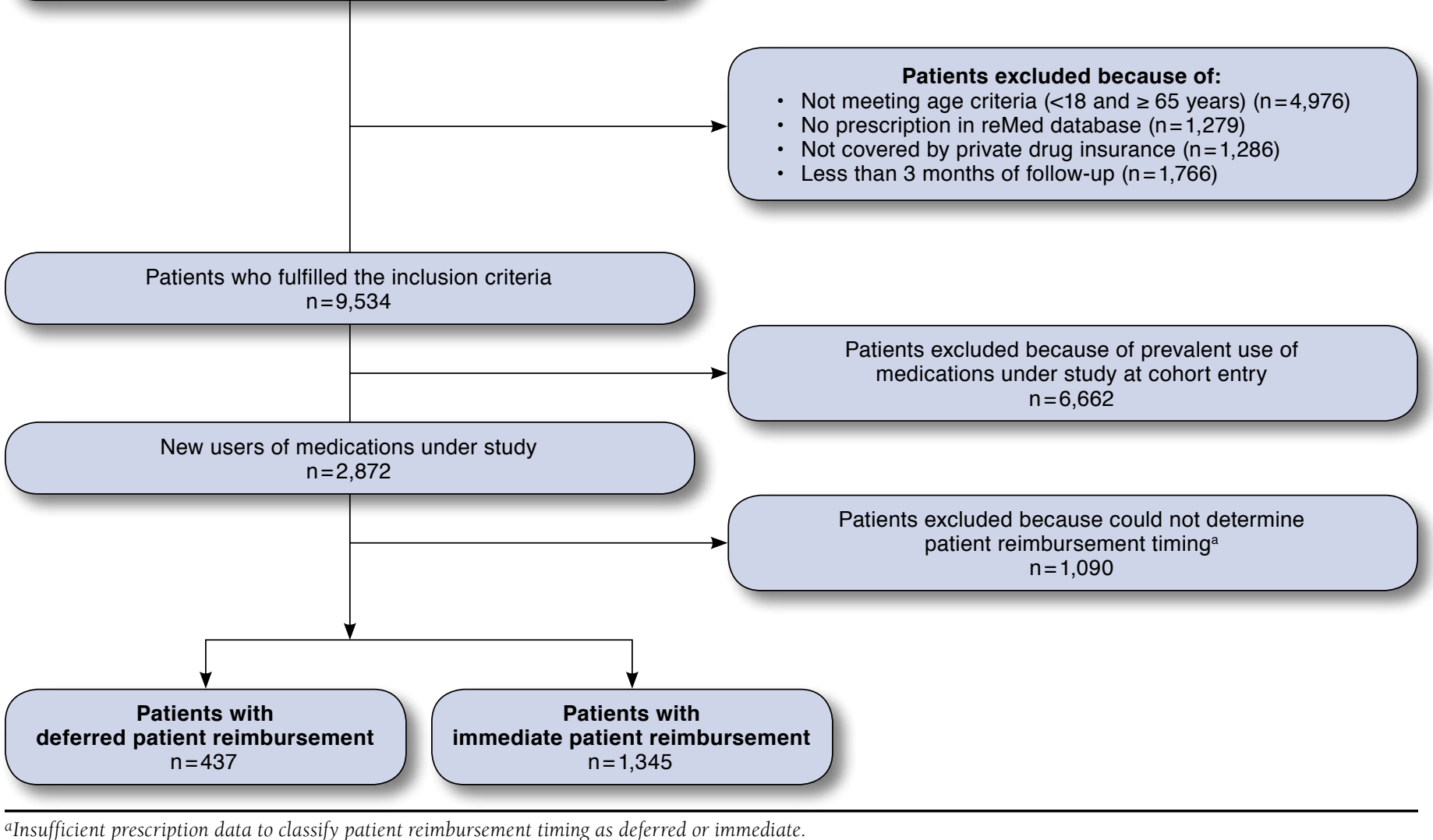

ansufficient prescription data to classify patient reimbursement timing as deferred or immediate.

The patient out-of-pocket expense analysis was restricted to patients with immediate patient reimbursement, since it was not possible to calculate the patient's contribution in cases of deferred patient reimbursement. We estimated the means and SDs of the PDCs within each of the 5 categories of patient out-of-pocket expenses for the medication under study and for all medications dispensed the same day as the medication under study. As above, linear regression models with a backward selection procedure were used to estimate the association between patient out-of-pocket expenses and adherence while adjusting for age, sex, BMI, smoking status, and the number of different medications filled in the year before cohort entry. It should be noted that we did not adjust for the drug class in our analysis because the level of patient out-of-pocket expenses is directly linked to the price of the medication, and the class of medication determines the price of the medication.

\section{Results}

As shown in Figure 1, 18,841 patients were registered in reMed when we selected the study cohort. We excluded 9,307 patients because they did not meet the inclusion criteria; 6,662 patients who used the medication under study before cohort entry; and 1,090 patients because it was not possible to assess their patient reimbursement timing due to lack of data.

Among the 1,782 patients included in the study, 1,345 (75.5\%) were classified as immediate patient reimbursement, and 437 (24.5\%) were classified as deferred patient reimbursement. Of those included in the study, more than $40 \%$ of patients were aged 35-49 years; more than 26\% were men; and more than $15 \%$ were smokers (Table 1). The 2 groups were similar in the majority of variables except for calendar year at cohort entry and BMI.

Among new users of the 10 most prescribed drug classes for chronic diseases in reMed, the mean (SD) adherence to medications was $38.7 \%( \pm 35.3 \%)$ in patients with immediate patient 


\begin{tabular}{|c|c|c|c|c|c|}
\hline \multirow[b]{2}{*}{ Number of patients } & \multicolumn{2}{|c|}{$\begin{array}{c}\text { Deferred Patient } \\
\text { Reimbursement } \\
\text { n (\%) }\end{array}$} & \multicolumn{2}{|c|}{$\begin{array}{c}\text { Immediate Patient } \\
\text { Reimbursement } \\
\text { n (\%) }\end{array}$} & \multirow[t]{2}{*}{$P$ Valu } \\
\hline & 437 & $(100.0)$ & 1,345 & $(100.0)$ & \\
\hline \multicolumn{6}{|l|}{ At Cohort Entry } \\
\hline Age (years) & & & & & 0.188 \\
\hline $18-34$ & 121 & $(27.7)$ & 419 & $(31.1)$ & \\
\hline $35-49$ & 187 & $(42.8)$ & 583 & $(43.4)$ & \\
\hline $50-64$ & 129 & $(29.5)$ & 343 & $(25.5)$ & \\
\hline Male & 133 & $(30.4)$ & 348 & $(25.9)$ & 0.062 \\
\hline Calendar year at cohort entry & & & & & $<0.001$ \\
\hline 2008 & 47 & $(10.8)$ & 63 & $(4.7)$ & \\
\hline 2009 & 55 & $(12.6)$ & 181 & $(13.5)$ & \\
\hline 2010 & 110 & $(25.2)$ & 386 & $(28.7)$ & \\
\hline 2011 & 133 & $(30.4)$ & 357 & $(26.5)$ & \\
\hline 2012 & 92 & $(21.0)$ & 358 & $(26.6)$ & \\
\hline Smoking status at recruitment in reMed & & & & & 0.355 \\
\hline Nonsmoker & 230 & $(52.6)$ & 735 & $(54.6)$ & \\
\hline Ex-smoker & 140 & $(32.0)$ & 376 & $(28.0)$ & \\
\hline Smoker & 67 & $(15.4)$ & 233 & $(17.3)$ & \\
\hline Missing & 0 & $(0.0)$ & 1 & $(0.1)$ & \\
\hline BMI at reMed recruitment & & & & & 0.008 \\
\hline Underweight & 8 & $(1.8)$ & 34 & $(2.5)$ & \\
\hline Normal & 201 & $(46.0)$ & 536 & $(39.8)$ & \\
\hline Overweight & 143 & $(32.7)$ & 399 & $(29.7)$ & \\
\hline Obese & 74 & $(17.0)$ & 328 & $(24.4)$ & \\
\hline Missing & 11 & $(2.5)$ & 48 & $(3.6)$ & \\
\hline Medication classes dispensed at cohort entry & & & & & 0.779 \\
\hline Antidepressants & 76 & $(17.4)$ & 199 & $(14.8)$ & \\
\hline Antiepileptics & 48 & $(11.0)$ & 155 & $(11.5)$ & \\
\hline Antihypertensives & 27 & $(6.2)$ & 94 & $(7.0)$ & \\
\hline Antipsychotics & 23 & $(5.3)$ & 73 & $(5.4)$ & \\
\hline Treatment for asthma and COPDa & 81 & $(18.5)$ & 264 & $(19.6)$ & \\
\hline Anticoagulants & 5 & $(1.1)$ & 20 & $(1.5)$ & \\
\hline Proton pump inhibitors & 117 & $(26.8)$ & 351 & $(26.1)$ & \\
\hline Oral antidiabetics & 10 & $(2.3)$ & 49 & (3.6) & \\
\hline Statins & 34 & $(7.8)$ & 84 & $(6.3)$ & \\
\hline Thyroid hormones & 16 & $(3.6)$ & 56 & $(4.2)$ & \\
\hline \multicolumn{6}{|l|}{ In the Year Before Cohort Entry } \\
\hline \multicolumn{6}{|l|}{ Filled prescriptions to treat } \\
\hline Diabetes & 22 & $(5.1)$ & 81 & $(6.0)$ & 0.422 \\
\hline Hypertension & 60 & $(13.7)$ & 197 & $(14.7)$ & 0.636 \\
\hline Cardiovascular diseases & 20 & $(4.6)$ & 69 & $(5.1)$ & 0.645 \\
\hline Respiratory diseases & 74 & $(16.9)$ & 255 & $(19.0)$ & 0.343 \\
\hline Gastrointestinal diseases & 60 & $(13.7)$ & 206 & $(15.3)$ & 0.418 \\
\hline Inflammation & 123 & $(28.2)$ & 384 & $(28.6)$ & 0.871 \\
\hline Dyslipidemia & 55 & $(12.6)$ & 137 & $(10.2)$ & 0.160 \\
\hline Anxiety and depression & 119 & $(27.2)$ & 337 & $(25.1)$ & 0.365 \\
\hline Number of different medications dispensed, ${ }^{b}$ mean [SD] & 4.5 & [3.3] & 4.7 & [3.7] & 0.222 \\
\hline Follow-up (days), mean [SD] & 296.3 & {$[90.7]$} & 293.2 & [91.8] & 0.541 \\
\hline
\end{tabular}




\begin{tabular}{|c|c|c|}
\hline $\begin{array}{l}\text { Ass } \\
\text { Reil } \\
\text { Adr } \\
\text { Me }\end{array}$ & \multicolumn{2}{|c|}{$\begin{array}{l}\text { Association Between Patient } \\
\text { Reimbursement Timing and } \\
\text { Adherence to Prescribed } \\
\text { Medications, as Measured by PDC }\end{array}$} \\
\hline & $\begin{array}{c}\text { Adjusted Mean } \\
\text { Difference in PDC (\%) } \\
n=1,782\end{array}$ & $95 \%$ CI \\
\hline $\begin{array}{l}\text { Deferred vs. immediate } \\
\text { patient reimbursement }\end{array}$ & 0.0 & -3.0 to 3.0 \\
\hline \multicolumn{3}{|l|}{ Age (years) } \\
\hline $18-34$ & Reference & \\
\hline $35-49$ & 3.0 & 0.0 to 6.0 \\
\hline $50-64$ & 8.0 & 4.0 to 12.0 \\
\hline \multicolumn{3}{|l|}{ BMI at reMed recruitment } \\
\hline Underweight & 1.0 & -9.0 to 10.0 \\
\hline Normal & Reference & \\
\hline Overweight & 3.0 & 0.0 to 6.0 \\
\hline Obese & 3.0 & 0.0 to 7.0 \\
\hline \multicolumn{3}{|c|}{ Medication under study at cohort entry } \\
\hline Antidepressants & 27.0 & 23.0 to 31.0 \\
\hline Antihypertensive drugs & 31.0 & 25.0 to 37.0 \\
\hline Antipsychotics & 11.0 & 4.0 to 17.0 \\
\hline $\begin{array}{l}\text { Treatment for asthma } \\
\text { and COPDa }\end{array}$ & -11.0 & -15.0 to -7.0 \\
\hline Antithrombotics & 37.0 & 25.0 to 49.0 \\
\hline Proton pump inhibitors & Reference & \\
\hline Oral antidiabetics & 33.0 & 25.0 to 42.0 \\
\hline Statins & 48.0 & 42.0 to 53.0 \\
\hline Thyroid hormones & 55.0 & 47.0 to 62.0 \\
\hline \multicolumn{3}{|c|}{$\begin{array}{l}\text { aInhaled corticosteroids (ICS), long-acting beta agonists (LABA), ICS +LABA, } \\
\text { anticholinergics. } \\
\text { BMI= body mass index; } C I=\text { confidence interval; } C O P D=\text { chronic obstructive pul - } \\
\text { monary disease; } P D C=\text { proportion of days covered. }\end{array}$} \\
\hline
\end{tabular}

reimbursement and 39.4\% ( $\pm 35.3 \%)$ for patients with deferred patient reimbursement. As shown in Table 2, after adjusting for confounding variables, we found no significant difference in adherence between patients with deferred and immediate patient reimbursement (difference in PDC, 0.0\%; 95\% confidence interval $[\mathrm{CI}],-3.0$ to 3.0).

Table 3 presents medication adherence for each selected medication according to the level of patient out-of-pocket expense. For the medication under study, the mean adherence was $38.4 \%$ for patients with no patient out-of-pocket expenses; $45.9 \%$ for patients with low patient out-of-pocket expenses (\$0.01-\$3.59); and $28.0 \%$ for patients with the highest level of patient out-of-pocket expenses (\$14.41-\$89.99). Similar trends were found when we considered patient out-of-pocket expenses related to all medications dispensed at cohort entry.

For the highest quartile of patient out-of-pocket expenses for the medication under study (\$14.41-\$89.99), we examined the range of medication adherence within this quartile by subdividing it in 4 subgroups of equal size. The level of adherence for these 4 subgroups were, respectively, $32.0 \%$ ( $\pm 0.3 \%$ ), $26.7 \%$

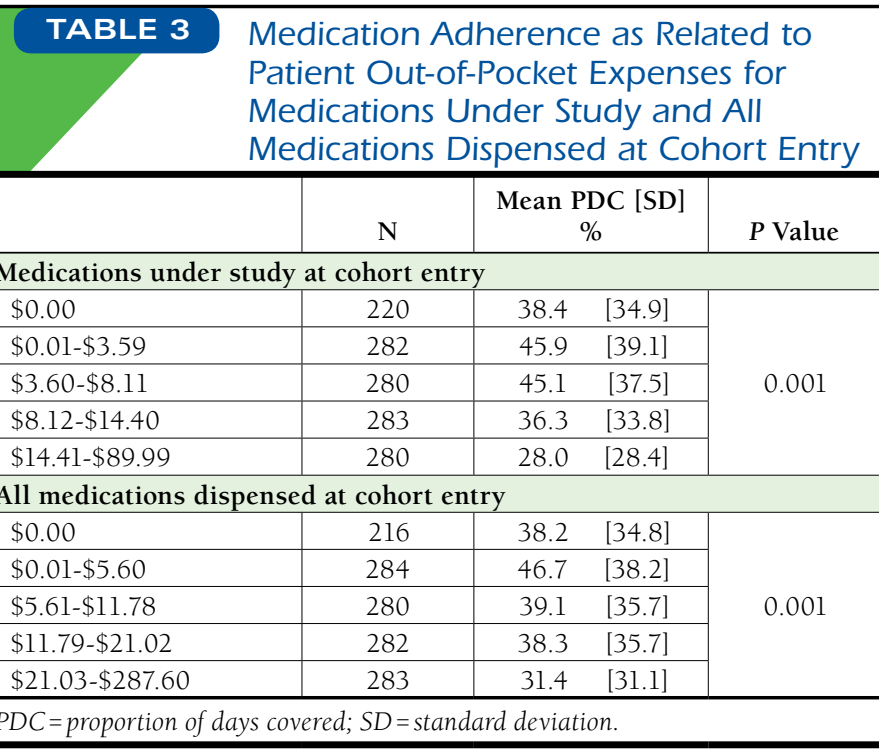

$( \pm 0.3 \%), 24.1 \%( \pm 0.1 \%)$, and $29.1 \%( \pm 0.1 \%)$. A 1 -way ANOVA found no difference on the level of adherence among the 4 subgroups $\left(F_{3,276}=1.01, P=0.39\right)$. Similarly, we found no difference on the level of adherence among the 4 subgroups of the highest quartile of patient out-of-pocket expenses (\$21.03-\$287.60) when we considered all medications dispensed at cohort entry $\left(\mathrm{F}_{3,276}=2.38, P=0.07\right)$.

As shown in Table 4, after adjusting for confounding variables, we found that adherence in patients with the 2 highest levels of patient out-of-pocket expenses for the medication under study were significantly lower than in those with a low level of patient out-of-pocket expenses (\$0.01-3.59), with differences being $-19.0 \%$ (95\% CI, -24.0 to -13.0$)$ and $-10.0 \%(95 \%$ CI, -16.0 to -4.0), respectively. However, we also found that adherence in patients with a low level of patient out-of-pocket expenses for the medication under study were significantly higher than adherence in patients with no patient out-of-pocket expenses (difference, $-9.0 \%$; 95\% CI, -15.0 to -2.0 ). Similar results were found when we considered patient out-of-pocket expenses related to all medications dispensed at cohort entry.

\section{Discussion}

The results of this study show that patient reimbursement timing (deferred vs. immediate patient reimbursement) had no impact on adherence to medications in patients enrolled in private drug insurance plans. However, we found that the level of patient out-of-pocket expense did have an impact on adherence: patients who paid small amounts were significantly more adherent than those who paid large amounts and those who had no patient out-of-pocket expenses.

The absence of an impact of deferred patient reimbursement on medication adherence, as observed in this study, is likely to be explained by the relatively rapid and automatic 


\begin{tabular}{|c|c|c|}
\hline \multicolumn{3}{|c|}{$\begin{array}{l}\text { Association Between Patient Out- } \\
\text { of-Pocket Expenses and Medication } \\
\text { Adherence for Medications Under } \\
\text { Study and All Medications Dispensed at } \\
\text { Cohort Entry }\end{array}$} \\
\hline & $\begin{array}{c}\text { Adjusted Mean } \\
\text { Difference in PDC (\%) } \\
\mathbf{n}=1,345\end{array}$ & $95 \%$ CI \\
\hline \multicolumn{3}{|c|}{ Medications under study at cohort entry } \\
\hline \multicolumn{3}{|c|}{ Patient out-of-pocket expenses (\$) } \\
\hline$\$ 0.00$ & $-9.0^{\mathrm{a}}$ & -15.0 to -3.0 \\
\hline$\$ 0.01-\$ 3.59$ & Reference & \\
\hline$\$ 3.60-\$ 8.11$ & $-2.0^{\mathrm{a}}$ & -8.0 to 4.0 \\
\hline$\$ 8.12-\$ 14.40$ & $-10.0^{\mathrm{a}}$ & -16.0 to -4.0 \\
\hline$\$ 14.41-\$ 89.99$ & $-19.0^{\mathrm{a}}$ & -25.0 to -13.0 \\
\hline \multicolumn{3}{|c|}{ All medications dispensed at cohort entry } \\
\hline \multicolumn{3}{|c|}{ Patient out-of-pocket expenses (\$) } \\
\hline$\$ 0.00$ & $-9.0^{\mathrm{a}}$ & -15.0 to -2.0 \\
\hline$\$ 0.01-\$ 5.60$ & Reference & \\
\hline$\$ 5.61-\$ 11.78$ & $-8.0^{\mathrm{a}}$ & -14.0 to -2.0 \\
\hline$\$ 11.79-\$ 21.02$ & $-8.0^{\mathrm{a}}$ & -14.0 to -2.0 \\
\hline$\$ 21.03-\$ 287.60$ & \begin{tabular}{|c|}
$-15.0^{\mathrm{a}}$ \\
\end{tabular} & -21.0 to -9.0 \\
\hline \multicolumn{3}{|c|}{$\begin{array}{l}\text { adjusted for age, sex, body mass index, smoking status, and the number of } \\
\text { different medications filled in the year before cohort entry. } \\
C I=\text { confidence interval; } P D C=\text { proportion of days covered. }\end{array}$} \\
\hline
\end{tabular}

reimbursement of prescription expenses by insurance companies in Quebec. This minimizes copayment-like effects on adherence that have been shown to be significantly associated with a decrease in medication adherence (2\%-6\% decrease in adherence per $\$ 10$ increase in copayment). ${ }^{6-18}$ The results of this analysis on patient reimbursement timing are in agreement with the published literature on the impact of patient out-ofpocket expenses on medication adherence. If the reimbursement is quick enough, patients do not have the impression that they have to pay more than if they had to pay only the copayment/deductible at the point of service.

The inverse relationship between patient out-of-pocket expense and medication adherence observed in patients with out-of-pocket expenses is in line with the results of other studies. Indeed, most studies have demonstrated that a $\$ 10$ increase in copayment is significantly associated with a decrease in medication adherence by $2 \%-6 \% \cdot{ }^{6-18}$ However, in this study, we also observed that patients with no out-of-pocket expenses were less adherent than those with small out-of-pocket expenses. This finding may be of interest for designers of value-based insurance plans where chronic patients are incentivized with low copayment. We also have to acknowledge that these results are contrary to those reported by studies that have shown that the reduction or the elimination of patient out-of-pocket expenses improved medication adherence. ${ }^{26-29}$ For example, Choudhry et al. (2011) found that the elimination of copayments for preventive medicine after myocardial infarc- tion in a private drug insurance plan significantly improved the level of adherence to antihypertensive medications. ${ }^{29}$ However, we can hypothesize that patients with no patient out-of-pocket expenses at the point of service might be less adherent because they place less value on their medications than do patients who must pay even a small amount, as described by the behavioral hazard model..$^{30}$

\section{Limitations}

Our results should be interpreted in light of the following limitations. We used claims data to assess adherence, but this does not necessarily represent the actual consumption of prescribed medications. Furthermore, residual confounding effects might be present, since we were unable to adjust for race, ethnicity, family income, level of education, comorbidity, or total medication cost for all medications-variables that have been shown in other studies to be associated with medication adherence. ${ }^{31-33}$ Moreover, we were not able to adjust for the level of patient out-of-pocket expenses, since it was not available for patients with deferred patient reimbursement. However, there is no reason to believe that the level of patient out-of-pocket expenses is associated with patient reimbursement timing. Patients who need to fill an insurance claim to have their medications reimbursed were not included in our cohort because they are not included in reMed, and our results should not be generalized to this subgroup of patients. Finally, although the present results can be generalized to workers and their family members with private drug insurance in Quebec, caution must be exercised in extending this generalization to patients on a public drug insurance plan.

Despite these limitations, our study has the following important strengths. This study is the first to compare medication adherence among patients with deferred and immediate patient reimbursement at the point of service. Also, the reMed database provided the possibility to study patients with drug insurance plans from several insurance companies, which differed in terms of coinsurance and deductibles, thereby increasing the generalizability of the results.

\section{Implications for Policy and Further Research}

Our results suggest that patient out-of-pocket expenses should be minimized to improve medication adherence as do valuebased insurance plans where chronic patients are incentivized with low copayment.

The work presented in this article opens a variety of research perspectives. The inclusion of patients covered by public drug insurance would increase the sample size and increase the external validity of the study. Also, it would be interesting to increase the size of the cohort to study the association between the level of patient out-of-pocket expenses and adherence to specific drug classes and see whether certain drug classes are more or less affected by the level of patient out-ofpocket expenses. 


\section{Conclusions}

Overall, our study has shown that patient reimbursement timing does not have an impact on medication adherence among patients with private drug insurance. However, we found that patients with high out-of-pocket expenses and those with no out-of-pocket expenses were less adherent than patients with small out-of-pocket expenses. Therefore, drug insurers and employers must be cautious when implementing patient out-ofpocket expense plans that might affect adherence in the short term and patient health and productivity in the long term.

\section{Authors}

FRANÇOIS DESPRÉS, BSc, Faculty of Pharmacy, University of Montréal, Montréal, Québec, Canada; AMÉLIE FORGET, MSc, Research Center, Hôpital du Sacré-Coeur de Montréal and Faculty of Pharmacy, Université de Montréal, Québec, Canada; FATIMAZOHRA KETTANI, MSc, Research Center, Hôpital du Sacré-Coeur de Montréal, and Faculty of Pharmacy, Université de Montréal, Montréal, Québec, Canada; and LUCIE BLAIS, PhD, Faculty of Pharmacy, Université de Montréal, and Research Center, Hôpital du Sacré-Coeur de Montréal, Montréal, Québec, Canada.

AUTHOR CORRESPONDENCE: Lucie Blais, PhD, Université de Montréal, Faculté de Pharmacie, C.P. 6128, succursale Centre-ville, Montréal (Québec), Canada, H3C 3J7. Tel.: 514.343.6111 (ext. 3786); Fax: 514.343.6120; E-mail: lucie.blais@umontreal.ca.

\section{DISCLOSURES}

This study was funded by Pfizer Canada, Montréal, Québec, Canada. Blais received research grants or honorarium from AstraZeneca, Pfizer Canada, Sanofi, Novartis, Almirall, GlaxoSmithKline, and Merck for research projects and co-chairs the AstraZeneca Endowment Pharmaceutical Chair in Respiratory Health. Després, Kettani, and Forget have no competing interests to declare.

All authors contributed to the concept and design of the study. Data were collected by Blais and Forget. Data analysis was conducted by Després. The manuscript was written by Després and revised by all authors.

\section{REFERENCES}

1. Burkhart PV, Sabate E. Adherence to long-term therapies: evidence for action. J Nurs Scholarsh. 2003;35(3):207.

2. Nichols-English G, Poirier S. Optimizing adherence to pharmaceutical care plans. J Am Pharm Assoc (Wash). 2000;40(4):475-85.

3. Vermeire E, Hearnshaw H, Van Royen P, et al. Patient adherence to treatment: three decades of research. A comprehensive review. J Clin Pharm Ther. 2001;26(5):331-42.

4. Osterberg L, Blaschke T. Adherence to medication. N Engl J Med. 2005;353(5):487-97.

5. Jin J, Sklar GE, Min Sen Oh V, Chuen Li S. Factors affecting therapeutic compliance: a review from the patient's perspective. Ther Clin Risk Manag. 2008;4(1):269-86.

6. Domino ME, Martin BC, Wiley-Exley E, et al. Increasing time costs and copayments for prescription drugs: an analysis of policy changes in a complex environment. Health Serv Res. 2011;46(3):900-19.
7. Patterson ME, Blalock SJ, Smith AJ, Murray MD. Associations between prescription copayment levels and beta-blocker medication adherence in commercially insured heart failure patients 50 years and older. Clin Ther. 2011;33(5):608-16.

8. Maciejewski ML, Bryson CL, Perkins M, et al. Increasing copayments and adherence to diabetes, hypertension, and hyperlipidemic medications. Am J Manag Care. 2010;16(1):e20-e34.

9. Yoon J, Ettner SL. Cost-sharing and adherence to antihypertensives for low and high adherers. Am J Manag Care. 2009;15(11):833-40.

10. Chernew M, Gibson TB, Yu-Isenberg K, Sokol MC, Rosen AB, Fendrick AM. Effects of increased patient cost sharing on socioeconomic disparities in health care. J Gen Intern Med. 2008;23(8):1131-36.

11. Colombi AM, Yu-Isenberg K, Priest J. The effects of health plan copayments on adherence to oral diabetes medication and health resource utilization. J Occup Environ Med. 2008;50(5):535-41.

12. Ye X, Gross CR, Schommer J, Cline R, St Peter WL. Association between copayment and adherence to statin treatment initiated after coronary heart disease hospitalization: a longitudinal, retrospective, cohort study. Clin Ther. 2007;29(12):2748-57.

13. Cole JA, Norman H, Weatherby LB, Walker AM. Drug copayment and adherence in chronic heart failure: effect on cost and outcomes. Pharmacotherapy. 2006;26(8):1157-64.

14. Gibson TB, Mark TL, Axelsen K, Baser O, Rublee DA, McGuigan KA. Impact of statin copayments on adherence and medical care utilization and expenditures. Am J Manag Care. 2006;12(Spec no.):SP11-19.

15. Gibson TB, Mark TL, McGuigan KA, Axelsen K, Wang S. The effects of prescription drug copayments on statin adherence. Am J Manag Care. 2006;12(9):509-17.

16. Taira DA, Wong KS, Frech-Tamas F, Chung RS. Copayment level and compliance with antihypertensive medication: analysis and policy implications for managed care. Am J Manag Care. 2006;12(11):678-83.

17. Gibson TB, Song X, Alemayehu B, et al. Cost sharing, adherence, and health outcomes in patients with diabetes. Am J Manag Care. 2010;16(8):589-600.

18. Schneeweiss S, Patrick AR, Maclure M, Dormuth CR, Glynn RJ. Adherence to statin therapy under drug cost sharing in patients with and without acute myocardial infarction: a population-based natural experiment. Circulation. 2007;115(16):2128-35.

19. Régie de l'assurance maladie du Québec. Rapport annuel de gestion 2010-2011. 2011. Available at: http://www.ramq.gouv.qc.ca/SiteCollection Documents/citoyens/fr/rapports/rappannl01l-fr.pdf. Accessed

February 13, 2016.

20. Assayag J, Forget A, Kettani FZ, Beauchesne MF, Moisan J, Blais L. The impact of the type of insurance plan on adherence and persistence with antidepressants: a matched cohort study. Can J Psychiatry. 2013;58(4):233-39.

21. Cyr MC, Beauchense MF, Lemiere C, Blais L. Comparison of the adherence and persistence to inhaled corticosteroids among adult patients with public and private drug insurance plans. J Popul Ther Clin Pharmacol. 2013;20(1):e26-41.

22. Despres F, Perreault S, Lalonde L, Forget A, Kettani FZ, Blais L. Impact of drug plans on adherence to and the cost of antihypertensive medications among patients covered by a universal drug insurance program. Can J Cardiol. 2014;30(5):560-67.

23. Hess LM, Raebel MA, Conner DA, Malone DC. Measurement of adherence in pharmacy administrative databases: a proposal for standard definitions and preferred measures. Ann Pharmacother. 2006;40(7-8):1280-88.

24. Zeng F, Patel BV, Andrews L, Frech-Tamas F, Rudolph AE. Adherence and persistence of single-pill $\mathrm{ARB} / \mathrm{CCB}$ combination therapy compared to multiple-pill ARB/CCB regimens. Curr Med Res Opin. 2010;26(12):2877-87. 
25. Austin PC. Bootstrap model selection had similar performance for selecting authentic and noise variables compared to backward variable elimination: a simulation study. J Clin Epidemiol. 2008;61(10):1009-17.

26. Kulik A, Desai NR, Shrank WH, et al. Full prescription coverage versus usual prescription coverage after coronary artery bypass graft surgery: analysis from the post-myocardial infarction free Rx event and economic evaluation (FREEE) randomized trial. Circulation. 2013;128(11 Suppl 1):S219-25.

27. Viswanathan M, Golin CE, Jones CD, et al. Closing the quality gap: revisiting the state of the science (vol. 4: medication adherence interventions: comparative effectiveness). Evid Rep Technol Assess (Full Rep). 2012;(208.4):1-685.

28. Viswanathan M, Golin CE, Jones CD, et al. Interventions to improve adherence to self-administered medications for chronic diseases in the United States: a systematic review. Ann Intern Med. 2012;157(11):785-95.
29. Choudhry NK, Avorn J, Glynn RJ, et al. Full coverage for preventive medications after myocardial infarction. N Engl J Med. 2011;365(22):2088-97.

30. Baicker K, Mullainathan S, Schwartzstein J. Behavioral hazard in health insurance*. Q J Econ. 2015;130(4):1623-67.

31. Alsabbagh MH, Lemstra M, Eurich D, et al. Socioeconomic status and nonadherence to antihypertensive drugs: a systematic review and metaanalysis. Value Health. 2014;17(2):288-96.

32. Mann DM, Woodward M, Muntner P, Falzon L, Kronish I. Predictors of nonadherence to statins: a systematic review and meta-analysis. Ann Pharmacother. 2010;44(9):1410-21.

33. Brown MT, Bussell JK. Medication adherence: WHO cares? Mayo Clin Proc. 2011;86(4):304-14. 